\title{
Projetos para uma pátria imaginada: - Brasil de José Bonifácio e Hipólito da Costa
}

\section{Isabel Lustosa}

Resumo: Antes mesmo da Independência, a ideia de um Brasil unido e coeso em torno de um centro político existia como um ideal romântico na mente de alguns brasileiros. Mas havia uma dissonância entre aqueles que, olhando de dentro, viam o Brasil como a sua pátria, região ou localidade em que nasceram; e outros que, educados na Europa, construíram seu imaginário em torno das imensas, reais ou idealizadas, potencialidades do Brasil unido do Oiapoque ao Chuí. Palavras-chave: Hipólito da Costa, nação, pertencimento, identidade.

Abstract: Even before the independence, the idea of a united and cohesive Brazil under a political center already existed as a romantic ideal in the mind of some Brazilians. But there was a disagreement between those who, looking inside, they saw Brazil as their homeland, region or locality in which they were born; and others that, educated in Europe, they built their imagination around the immense, real or idealized, potential of a united Brazil from Oiapoque to Chuí. Keywords: Hipólito da Costa, nation, collective belongingness, identity. 
A ideia de um Brasil unido e coeso em torno de um centro político existia como um ideal romântico nas mentes de alguns brasileiros antes mesmo da Independência. Havia uma dissonância entre aqueles que o viam de dentro como sua pátria, a região ou localidade em que nasceram, e aqueles brasileiros cultos, educados na Europa que, de fora, construíram seu imaginário em torno das imensas, reais ou idealizadas, potencialidades do Brasil. Esses brasileiros difundiram aqui, através de seus escritos e de sua atuação, a ideia de um Brasil unido do Oiapoque ao Chuí. E este ideal já vinha sendo construído bem antes da Independência.

\section{Já havia um Brasil antes da Independência?}

Um tema que tem sido trabalhado pela historiografia é o da existência ou não de uma Nação brasileira anterior ao Estado que se constituiu após a Independência. Richard Graham mapeou este debate questionando os que, como Oliveira Lima e José Honório Rodrigues, pretendem que a nação brasileira, na forma física que veio depois a assumir, já existia como projeto e vontade no espírito dos brasileiros antes mesmo da Independência. Graham lembra que, para os europeus, pelo menos até 1815, quando o Brasil foi elevado a reino, "Brasil" era simplesmente "a designação genérica das possessões portuguesas na América do Sul". ${ }^{1}$ Graham também questiona Benedict Anderson, quando este, em seu clássico livro Comunidades imaginadas, afirma que já existiam nações na América Latina antes da Independência e refere-se "ao aparecimento da consciência nacional americana, no final do século xviıI". ${ }^{2}$ Na visão de Graham foi o Estado criado depois da Independência que levou à formação da Nação, e não o contrário.

De fato, durante o século XVIII, seria praticamente impossível para um brasileiro de São Paulo, por exemplo, se sentir identificado com um habitante de São Luís do Maranhão ou do Rio Grande do Sul. Não só as distâncias eram imensas, como também a comunicação era quase nula. Dividir para reinar era a fórmula adotada pela Coroa portuguesa para melhor exercer o controle sobre sua principal colônia. 
Assim, as capitanias estavam praticamente isoladas, sem estradas que as unissem. Só em circunstâncias especiais, como a necessidade de escoar a produção de ouro e pedras preciosas para o porto do Rio de Janeiro e fazer circular as mercadorias necessárias para as vilas de Minas Gerais, é que se permitia a abertura de alguns caminhos. $^{3}$

Depois da chegada da Corte, em 1808, essa situação mudou radicalmente. Um dos efeitos mais importantes da instalação da sede da monarquia portuguesa no Rio de Janeiro foi o incremento das comunicações entre as províncias e a estreita ligação que se estabeleceu entre as que hoje compõem a região Sudeste: Rio de Janeiro, São Paulo e Minas. No entanto, não só as guerras da Independência como também as que ocorreram durante a Regência demonstraram que esta unidade se mantinha sob forte tensão e precária estabilidade e uma relativa verdadeira integração que só seria mesmo alcançada depois da segunda metade do século XIX. O ponto que defendo aqui é que se, para a maior parte o Brasil era apenas uma projeção idealizada, a ideia de um Brasil unido e coeso em torno de um centro político existia como um ideal romântico nas mentes de alguns brasileiros antes mesmo da Independência. Existia, de fato, uma dissonância entre aqueles que, de dentro do Brasil, viam como sua pátria a região ou localidade em que nasceram e aqueles brasileiros cultos, educados na Europa, que, de fora, construíram seu imaginário em torno das imensas, reais ou idealizadas, potencialidades do Brasil. A meu ver, foram esses brasileiros que difundiram aqui, através de seus escritos e de sua atuação, a ideia de um Brasil unido do Oiapoque ao Chuí. E este ideal já vinha sendo construído bem antes da Independência.

\section{Antecedentes: Pombal e d. Rodrigo}

Segundo nos revelou o estudo clássico de Maria de Lourdes Viana Lyra, em Portugal, fazia muito tempo havia gente pensando nas grandes possibilidades que adviriam para o país com a transferência da Corte para a América: os que desejavam o fortale-

Ver especialmente: LENHARO, Alcir. As tropas da moderação: o abastecimento da Corte na formação política do Brasil (1808-1842). 2. ed. Rio de Janeiro: Secretaria Municipal de Cultura, Turismo e Esportes, 1993. Coleção Biblioteca Carioca, v. 25; e DIAS, Maria Odila L. da Silva. A interiorização da Metrópole. In: A interiorização da metrópole e outros estudos. São Paulo: Alameda, 2005, p. 7-37.

162 - LUSTOSA, Isabel. Projetos para uma pátria imaginada 
cimento da Nação Portuguesa tendo por base o Brasil. ${ }^{4}$ Um dos argumentos de que se valiam era o de que o Brasil - distante dos conflitos da Europa e com sua imensa costa difícil de ser atacada - oferecia maiores condições de defesa e segurança para a Coroa. Esses ideólogos pensavam em construir um império transoceânico que recuperasse para Portugal as glórias de seu passado. Seus sentimentos eram partilhados pela maior parte dos brasileiros cultos. Afinal, antes de 1822, éramos todos portugueses.

Segundo Maria de Lourdes Lyra, desde o começo do século XviII a imagem do Brasil que circulava na Europa era uma imagem idealizada. Idealização que se alimentava não só dos relatos dos viajantes mas também da própria falta de expectativas dos portugueses, cada vez mais dependentes de sua mais importante colônia. O império americano lavava a alma portuguesa do humilhante status de nação de segunda ordem no contexto das monarquias europeias e a confortava com a ideia de um tesouro na América, uma terra prometida para onde a Coroa e o próprio povo de Portugal poderiam migrar a qualquer momento. As dimensões dessa terra eram tais que a ela só poderia caber o título de Império. ${ }^{5}$

A cooptação da juventude culta brasileira para esse projeto teria começado ainda com Pombal. A política de industrialização portuguesa preconizada por aquele ministro deveria ter por base as matérias-primas produzidas no Brasil. Para desenvolver e diversificar a produção agrícola da colônia americana, de forma que compensasse as oscilações dos rendimentos do quinto e a baixa do preço do açúcar, Pombal encomendou aos governadores e capitães-generais das principais capitanias a realização de estudos sobre a flora e a fauna brasileira e de levantamento de seus produtos mais comerciáveis. Com isto, como foi bem demonstrado por Maria Odila Dias, uma série de trabalhos geográficos e estatísticos foram então realizados por brasileiros formados em Coimbra. Estudos que seriam depois continuados sob a orientação de d. Rodrigo de Sousa Coutinho, o conde de Linhares, ministro do Reino de d. João. ${ }^{6}$ Na opinião de Maria Odila, tais estudos, que eram frequentemente acompanhados por relatórios de viagem, merecem ser analisados "como parte integrante do processo de formação de uma consciência nacional [,] pois revelam os conhecimentos de que os brasileiros daquele tempo dispunham sobre a realidade de sua terra já

LYRA, Maria de Lourdes Viana. A utopia do poderoso império. Portugal e Brasil: Bastidores da Política 1789-1822. Rio de Janeiro: Sette Letras, 1994.

DIAS, Maria Odila L. da Silva. Aspectos da llustração brasileira. In: A interiorização da metrópole e outros estudos. São Paulo: Alameda, 2005, p. 39-126.

Teresa revista de Literatura Brasileira [12|13]; São Paulo, p. 160-173, 2013•163 
no final do século XvinI". Seus autores foram formados na atmosfera do reformismo ilustrado do Antigo Regime que orientaria a política joanina e manteriam, até a Independência, um sentimento patriótico que os ligava a Portugal. ${ }^{7}$ A vinda da família real para o Brasil deu-lhes a impressão de que, finalmente, ia se concretizar o ideal de um grande império português centralizado na América. O processo de Independência provocaria uma violenta alteração nesse sentimento e representou uma ruptura bastante dolorosa para a maior parte do grupo.

Dentre aqueles brasileiros, destaco, como os que maior influência tiveram sobre a geração que fez a Independência, os nomes de José Bonifácio de Andrada e Hipólito da Costa. Ambos reforçaram seu sentido de pertencimento à grande pátria lusitana no ambiente ilustrado da Corte de Lisboa, tendo sempre em mente o Brasil. Em 1819, no discurso de despedida da Real Academia de Ciências de Lisboa, José Bonifácio, que viveu na Europa dos dezessete aos 56 anos, revela que o ufanismo dos brasileiros do tempo já se construía com base nas dimensões continentais do país e em suas supostas e/ou evidentes riquezas naturais.

É esta, ilustres acadêmicos, a derradeira vez, sim, a derradeira vez, com bom pesar o digo, que tenho a honra de ser o historiador de vossas tarefas literárias, e patrióticas; pois é forçoso deixar o antigo, que me adotou como filho, para ir habitar o novo Portugal, onde nasci. [...] Consola-me igualmente a lembrança de que da vossa parte pagareis a obrigação em que está todo o Portugal para com a sua filha emancipada, que precisa de por casa, repartindo com ela das vossas luzes, conselhos e instruções... E que país esse, senhores, para uma nova civilização e para novo assento das ciências! Que terra para um grande e vasto Império! [...] Riquíssimo nos três reinos da natureza, com o andar dos tempos nenhum outro país poderá correr parelhas com a nova Lusitânia. ${ }^{8}$

Note-se que, em 1819, o Andrada já falava do Brasil como o novo Portugal e como "filha emancipada que precisa por casa" - em 1815 o Brasil fora elevado a Reino -, e exalta suas dimensões e suas grandes riquezas. Não fala absolutamente em rompimento, mas em continuidade: em um processo do qual Portugal continuava a fazer parte no sentido de estimular o desenvolvimento do Brasil.

Só quando volta a São Paulo e se envolve nos problemas internos da província

7 Idem.

8 ANDRADA E SILVA, José Bonifácio de. Obras científicas, políticas e sociais de José Bonifácio de Andrada e Silva. Coligidas e reproduzidas por Edgard de Cerqueira Falcão. São Paulo: Revista dos Tribunais, 1963, p. 144.

164 • LUSTOSA, Isabel. Projetos para uma pátria imaginada 
é que José Bonifácio adota um sentido de pertencimento mais regional. Mesmo assim, tanto naquela despedida de Lisboa em 1819, quanto, dois anos depois, nas Lembranças e apontamentos do governo provisório para os senhores deputados da província de São Paulo, redigidas por ele e que seu irmão Antonio Carlos apresentaria nas Cortes de Lisboa, se empenharia pela integridade e indivisibilidade do Brasil. Esse seria também o seu maior esforço no governo e nos debates da Assembleia Constituinte de 1823, onde alguns deputados pugnavam pelo Federalismo. ${ }^{9}$

\section{Hipólito}

O outro importante dessa geração brasileira foi Hipólito José da Costa, que teve grande influência sobre os jornais e os jornalistas da Independência. Protagonizando uma biografia cheia de lances extraordinários e dono de uma inteligência prodigiosa, Hipólito, ao longo de sua atividade jornalística, produziu uma obra profunda de análise e crítica da realidade brasileira. A viagem aos Estados Unidos, onde viveu de 1798 a 180o, lhe proporcionou um contato direto com a grande experiência democrática e republicana que ali se vivia. Nos Estados Unidos ele se filiou à Maçonaria, o que também contribuiu para o desenvolvimento de maior abertura no sentido das expectativas de liberdade e de direitos. A volta a Portugal, em 180o, seria marcada por uma militância maçônica que acabaria por levá-lo à prisão. ${ }^{10}$

O Hipólito da Costa que se estabeleceu em Londres em 1805, depois de uma aventurosa fuga dos cárceres da Inquisição, chegou transformado por essas experiências. Os anos de vida na Inglaterra, o contato com suas instituições políticas e a própria atividade editorial completariam sua formação. Quando o Príncipe Regente, d. João, partiu com a Corte para o Brasil, em 18o8, Hipólito da Costa deu início à publicação de um jornal a que escolheu chamar de Correio Braziliense. Seu principal objetivo era trabalhar pela fixação definitiva da Corte no Rio de Janeiro, garantindo assim a supremacia do Brasil no contexto da nação portugue-

Cf. LUSTOSA, Isabel. Insultos impressos: a guerra dos jornalistas na Independência (1821-1823). São Paulo: Companhia das Letras, v. I, 2000; e As trapaças da sorte: ensaios de história política e de história cultural. Belo Horizonte: EDUFMG, 2004.

10 As duas experiências, a viagem à América e a prisão, foram narradas pelo próprio Hipólito da Costa em Diário de minha viagem à Filadélfia. Rio de Janeiro: Academia Brasileira de Letras, 1955; e Narrativa da perseguição. Porto Alegre: Associação Rio-Grandense de Imprensa, Universidade Federal do Rio Grande do Sul, 1974. 
sa. Ou seja, era dar concretude ao projeto do grande império luso-brasileiro com sede na América tal como vinha sendo pensado desde o tempo de Pombal por alguns ilustrados portugueses e brasileiros.

Um aspecto que merece ser destacado na biografia de Hipólito da Costa é o pouco tempo que ele viveu no Brasil em contraste com o tanto que ele escreveu sobre o Brasil. Hipólito nasceu em 25 de março de 1774, na colônia de Sacramento, na Cisplatina, região que hoje pertence ao Uruguai, viveu ali até os três anos, passou infância e adolescência no Rio Grande do Sul - cerca de catorze anos - e foi para Coimbra, iniciando uma trajetória que o manteria fisicamente afastado do Brasil até a sua morte, aos 49 anos, em 1823. Não se tem notícia de que ele tenha estado alguma vez no Rio de Janeiro, em São Paulo ou Minas Gerais e, menos provavelmente ainda, na Bahia, no Recife, em São Luís ou Belém do Pará. Enfim, do Brasil, Hipólito só conheceu o Rio Grande do Sul, região de fronteira que, durante um longo período de nossa história, foi alvo de disputas com as colônias espanholas do Prata. No entanto, Hipólito foi, certamente, dos homens de sua geração, o que mais escreveu sobre o Brasil. Seu jornal, o Correio Braziliense, foi publicado em Londres entre 1808 e 1822, duas datas decisivas para a nossa história. Assim, durante catorze anos, um brasileiro que nasceu no Uruguai, formou-se em Portugal, conheceu os Estados Unidos antes e melhor que qualquer outro de seu tempo, e que viveu a maior parte de sua vida na Inglaterra, dedicou-se a escrever um jornal para o Brasil.

O que nos leva à questão inicial? Qual Brasil? Um Brasil que se alimentava daquele ideal romântico que sustentava o projeto do Império luso-brasileiro. Ideal que, por sua vez, se construíra sobre a base sólida de estudos científicos tais como já bem o demonstrou Maria Odila Dias e que tinham uma finalidade muito prática: a exploração econômica e racional dos recursos naturais do Brasil. ${ }^{11}$

\section{O Brasil nas páginas do Correio Braziliense}

Hipólito foi um observador atento e um leitor compulsivo que examinou e comentou, ao longo dos catorze anos em que durou o Correio Braziliense, uma vastíssima documentação. Os documentos reunidos no Correio cobrem quase tudo que estava acontecendo de relevante em termos políticos e econômicos na Europa

DIAS, Maria Odila L. da Silva. Aspectos da llustração brasileira. In: A interiorização da metrópole e outros estudos. Op. cit.

166. LUSTOSA, Isabel. Projetos para uma pátria imaginada 
e nas Américas durante o período que vai de 1808 a 1822, com ênfase no que se passava no Brasil e em Portugal. Sua vontade de ver adotado no Brasil o modelo liberal inglês fez com que fosse um grande divulgador da Constituição inglesa e de obras sobre o assunto.

Alguns assuntos percorrem a coleção do Correio Braziliense do começo ao fim. Creio que os mais intensivamente trabalhados são os temas da má administração do reino português, da corrupção e do filhotismo que vieram com a Corte de Portugal para o Rio de Janeiro. Desde os primeiros números, Hipólito insiste que a estada da Corte no Brasil deva ter como papel primordial o consolidar de vez os domínios portugueses em um só Império. Mas para viabilizar esse projeto seria necessário dar-lhe unidade administrativa, estabelecendo em toda parte as mesmas leis e racionalizando as despesas com a administração pública.

O "mau emprego que se faz das rendas publicas" seria um tema recorrente em seu jornal. Em julho de 1810, ele lembrava que o grande déficit nas finanças do Brasil era uma barreira insuperável à sua prosperidade. Apesar de o governo pedir somas expressivas de dinheiro emprestado, vivia sem crédito e não conseguia empreender os melhoramentos de que dependia a futura prosperidade do país, como, por exemplo, a abertura de estradas. O que faltava era, constatava ele já em junho de 1809, dada a extensão do território, o estabelecimento de um plano que implicasse a "ramificação" da administração das finanças no Brasil, ligando suas diferentes partes, através da correspondência com o erário dos coletores das rendas públicas estabelecidos nas diferentes capitanias. Enfim, era preciso organizar a cobrança dos tributos e unificar o erário por meio de uma administração central na Corte. ${ }^{12}$

Durante todo o tempo em que durasse o jornal, Hipólito atacaria duramente a tradição do governo português de conceder monopólios que tiveram continuidade no Brasil. Para ele, os únicos que se beneficiavam com essas práticas eram aqueles que ganhavam a concessão, pois para o Estado ela era totalmente desvantajosa. A seu ver "não há nada tão capaz de sufocar a indústria, de destruir o espírito de emulação e de perpetuar os abusos, como os monopólios". Hipólito lembra que, ao contrário do Brasil, nos Estados Unidos não há concessão de monopólio para nenhum tipo de atividade econômica. ${ }^{13}$

COSTA, Hipólito da. Correio Braziliense, v. 2, n. 13, jun. 1809, p. 637. São Paulo/Brasília: Imprensa Oficial do Estado/Correio Braziliense. Edição fac-similar, 2001-2003. 
Outro aspecto precursor do pensamento de Hipólito são as suas reflexões sobre os danos que a escravidão causava à sociedade brasileira e as vantagens do trabalho livre. Acreditando que logo esse mal seria superado, ele falará, de forma recorrente, da importância de se estimular a imigração de europeus, artistas, agricultores mineiros, pescadores, homens de letras e trabalhadores em geral. Em dezembro de 1810, dizia que era preciso assegurar a liberdade pessoal e o direito de propriedade dos imigrantes através de leis "fixas e permanentes, e não de Decretos, e Alvarás, que um Secretário de Estado faz pela manhã, e que outro Secretário de Estado dispensa por um Aviso, na tarde do mesmo dia". ${ }^{14}$ Lembraria anos depois que era justamente por faltarem aqui aquelas garantias que os imigrantes vinham preferindo os Estados Unidos ao Brasil. ${ }^{15}$

Hipólito tinha uma perspectiva econômica da educação, insistindo sempre sobre a necessidade "de espalhar instrução útil no Brasil" e de que "a evolução do caráter nacional seria alcançada com medidas como o estabelecimento de uma Universidade no Brasil, a introdução geral das escolas de ler e escrever e a ampla circulação de jornais e periódicos, nacionais e estrangeiros" ${ }^{16}$ Também insistia na importância da formação de quadros de elite capazes de servir ao Estado e dizia que "não se pode formar políticos sem os estudos preliminares da sua ciência, a leitura da história e o conhecimento do que atualmente vai acontecendo no mundo, e para isso as obras periódicas são essenciais". ${ }^{17}$

Da sua perspectiva, se a liberdade de imprensa era fundamental para a ampliação dos horizontes das elites, era também essencial para a boa marcha dos negócios públicos. Um dos temas insistentemente trabalhados nas páginas do Correio é a necessidade de transparência das contas e dos negócios públicos, e citava como exemplo a Inglaterra, onde os planos de finanças do governo eram obrigatoriamente apresentados e discutidos no Parlamento. Durante as discussões, os jornais podiam opinar sobre o assunto, inserindo observações de outras pessoas. Com isto, conclui o jornalista, "um tal plano é discutido por toda a nação e o Ministro de finanças se pode auxiliar dos conselhos de todos os homens instruídos" ${ }^{18}$ Em Portugal, no entanto, não havendo um Parlamento e uma imprensa livre, todas

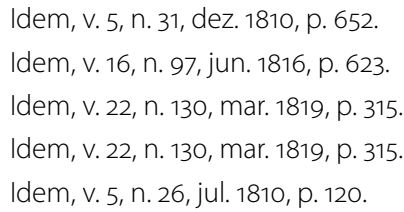


as decisões importantes eram tomadas em segredo e a ninguém era permitido examinar as contas públicas. A seu ver era necessário que aqueles gastos fossem feitos às claras e que as circunstâncias que ocasionassem a riqueza ou a pobreza do erário não deveriam "ser matéria de segredo de Gabinete" e que "o meio eficaz de coibir as más práticas é fazer com que elas sejam examinadas e discutidas em público". ${ }^{19}$

Em seus escritos Hipólito informa sobre a realidade de várias regiões do país, acompanhando os melhoramentos que vão sendo implementados. Assim é que tomamos conhecimento, em março de 1810 , de que fora introduzida na capitania do Rio Grande a cultura de "linho cânhamo". ${ }^{\circ} \mathrm{O}$ jornalista chama a atenção para a importância dessa cultura na confecção das cordas e velas essenciais para a Marinha. Em agosto de 1811, ele informa que fora criada uma biblioteca pública na Bahia, que ali se faziam subscrições a fim de mandar a Londres algum indivíduo "hábil", que aprendesse os novos métodos das escolas de Lancaster e Bell, e louva a criação de um novo estabelecimento para a educação de meninos pobres. ${ }^{21}$ Os melhoramentos implementados pelo intendente-geral de polícia do Rio de Janeiro são amplamente comentados no Correio: construção de novos chafarizes; e pontes de pedra em São Cristóvão; na rua do Senado e na praia do Flamengo; canalização das águas do rio Maracanã; limpeza de valas nas ruas da Cidade Nova; abertura de estradas, ligando Itaguaí à Real Fazenda de Santa Cruz; ligando Campos a Minas Gerais etc. $^{22}$

Em março de 1812, o Correio informa sobre as medidas tomadas pelo governador de Mato Grosso para melhorar as comunicações do interior do Brasil através dos rios. Que o Amazonas fora reconhecido como navegável, o que, a seu ver, promete muita prosperidade para aquela região. ${ }^{23}$ Em março de 1813 informa que na comarca de Porto Seguro abrira-se à navegação o rio Belmonte, o que facilitaria a comunicação desta capitania com as do centro $^{24}$ e, em outubro de 1818, que fora também aberto à navegação o rio Jequitinhonha, facilitando o comércio entre Minas e a Bahia. ${ }^{25}$ Em abril de 1815 , ele registra o estabelecimento de um correio

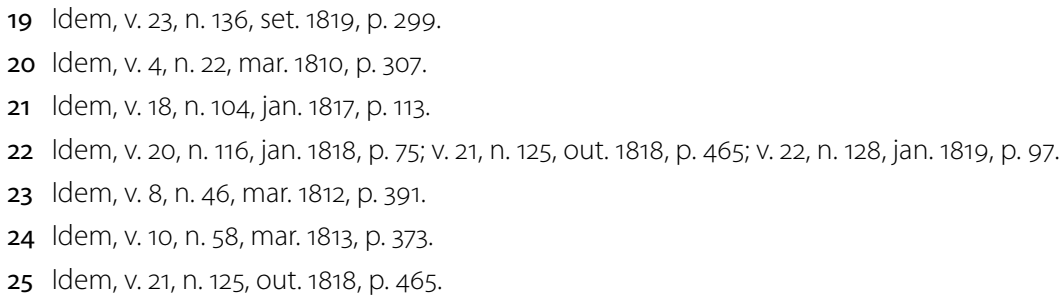


regular do Ceará para o Maranhão e que já se estaria organizando outro do Ceará para Pernambuco. ${ }^{26} \mathrm{Em}$ abril de 1818 , critica o fato de que a linha do correio entre o do Rio Grande e São Paulo tinha sido concedida sob a forma de monopólio a um indivíduo. ${ }^{27}$

Em janeiro de 1820, o jornalista saúda a iniciativa do Brasil de incentivar e patrocinar a ida de cientistas, professores, artistas, entre outros, ao país. A seu ver, essas "vistas de política liberal do Governo do Brasil" são muito importantes para o futuro do país, pois

estes sábios publicarão depois seus jornais, estes serão traduzidos na linguagem do país, e assim a indústria estrangeira suprirá a falta da nacional, porque é certo que, sem o conhecimento cabal dos recursos naturais do país, mal poderão os homens, que se acharem à testa do Governo, fazer uso dos meios físicos, que a natureza de seu terreno lhes oferecer, e já que as circunstâncias não permitem que se aproveitem os talentos dos naturais, pelo menos utilize-se a indústria estrangeira. ${ }^{28}$

Um dos projetos sobre o qual mais insistira Hipólito era o da necessária mudança da capital do Brasil para o interior. Em março de 1813, ele recomenda que, se os portugueses tivessem patriotismo e quisessem de fato agradecer ao Brasil que os acolheu, eles se estabeleceriam em uma região central, no interior do país, perto das cabeceiras dos grandes rios e construiriam ali uma nova cidade. O problema dessa cidade nascida no meio do "deserto" seria resolvido com a construção de estradas que se dirigissem a todos os portos de mar, ligando-a às principais povoações. Desta maneira, a capital do país serviria de ponto de reunião entre as partes mais distantes do Brasil. Com isto seriam lançados, conclui Hipólito, "os fundamentos do mais extenso, ligado, bem defendido e poderoso império que é possível que exista na superfície do Globo, no estado atual das nações que o povoam”. ${ }^{29}$

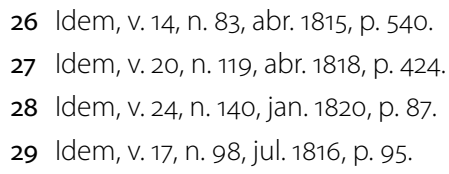




\section{Conclusão}

Creio que esse elenco de temas trabalhados por Hipólito da Costa em seu jornal é interessante para pensar como a ideia de um Brasil unido e coeso em torno de um centro político existia nas mentes de alguns brasileiros. Se considerarmos o imenso pragmatismo de toda a reflexão e de toda a ação de Hipólito da Costa no sentido de reforçar o Brasil enquanto sede do Reino de Portugal e de definir e fortalecer os contornos (inclusive físicos) da nação brasileira, minha hipótese sai fortalecida. Pois resta demonstrado que, mais do que para os que viviam aqui, às voltas com os problemas locais de suas comarcas e províncias, o Brasil, enquanto nação, era para Hipólito uma construção simbólica, uma utopia a ser concretizada, bem de acordo com a definição clássica de Eric Hobsbawm, para quem as nações são "criações culturais", ou de Benedict Anderson, que define nação como uma "ideia que se constrói”. ${ }^{30}$

Anderson lembra-nos de que "nem mesmo os membros das menores nações jamais conheceram a maioria dos seus compatriotas, nem os encontrarão, nem sequer ouvirão falar deles, embora na mente de cada um esteja viva a imagem de sua comunhão". ${ }^{11}$

A nação é comunidade imaginada, na medida em que mantemos uma relação de pertencimento com ela porque foi lá que nascemos, foi lá que teve origem a história de nossa família e é lá o lugar para onde pretendemos um dia voltar. Se a ideia de nação pertence exclusivamente a um período particular e historicamente recente, como diz Hobsbawm, e este caráter recente coincide, de acordo com Anderson, com a emergência do Iluminismo, podemos pensar o Brasil mais do que nunca como uma comunidade imaginada, ou, melhor ainda, como uma comunidade que se começava a imaginar. E Hipólito da Costa, que vivenciou o momento de eclosão desse espírito no mundo, por sua atuação no Correio Braziliense, foi tanto ator quanto personagem desse acontecimento. Cidadão do mundo, sua condição de estrangeiro conformou sua identidade tanto em Portugal, quanto nos Estados Unidos, quanto na Inglaterra e até mesmo com relação ao Brasil. Seu lugar nenhum no mundo, seu não pertencimento a nenhuma nação serviram como reforço à sua opção pelo Brasil, à sua identidade de brasileiro.

30 HOBSBAWM, Eric J. Nações e nacionalismo desde 1780: programa, mito e realidade. Rio de Janeiro: Paz e Terra, 1990; ANDERSON, Benedict. Nação e consciência nacional. São Paulo: Ática, 1989.

31 ANDERSON, Benedict. Nação e consciência nacional. Op. cit. 
Através das páginas do Correio Braziliense, Hipólito da Costa contribuiu decisivamente para reforçar a ideia de um Brasil que juntava as várias partes que até então haviam permanecido em estado latente de fragmentação em uma unidade política e simbólica. A meu ver ele pôde obter essa visão privilegiada a partir de alguns fatores. Ele via o Brasil a distância e estava alheio aos eventuais conflitos internos, produzindo a partir daí uma análise menos apaixonada do que quem aqui vivia. Outro fator é que Hipólito tinha construído sua identidade brasileira em oposição às identidades das pessoas dos países em que viveu em seu longo e definitivo afastamento do Brasil, assim tinha uma noção mais precisa do que fazia diferença entre ser brasileiro e ser português, norte-americano ou inglês, por exemplo. E, finalmente, pesa o fato de que foi através de seus estudos e da documentação que serviu de base aos tantos textos que Hipólito escreveu sobre seu país que ele formou uma ampla bagagem de conhecimentos sobre o Brasil, seus problemas e potencialidades. Por tudo isto, Hipólito pôde, de forma mais objetiva, estabelecer as características essenciais da nação brasileira e do modelo de organização política e administrativa que mais lhe convinha.

Como já se disse anteriormente, o que marca uma época não são as grandes obras dos grandes autores mas sim uma versão simplificada e vulgarizada delas, capaz de ser apreendida pelo senso comum dos contemporâneos. Homens influentes como José Bonifácio e Hipólito da Costa lideraram a difusão do ideal do Brasil poderoso formando uma única e integrada Nação. Esse pensamento circulou tanto através dos impressos mas também através das práticas normais de sociabilidade que então havia, reuniões da Maçonaria, em casa de particulares, em tabernas e nas praças.

Naturalmente que outras ideias que naquele momento predominavam no mundo também vieram aqui desaguar de forma vulgarizada. Nos jornais que participaram da campanha pela Independência, entre 1820 e 1823, as referências a expressões então correntes na Europa e nos Estados Unidos aparecem de forma generosa. Quase todos falam em Luzes, liberalismo, constitucionalismo, pacto social, bem geral, direitos do cidadão etc. Eram ideais que corriam o mundo e chegavam aqui pelos mais variados meios. No entanto, por si sós elas não levariam à Independência. Nem mesmo quando associadas às visões idealizadas do Brasil e de seu imenso potencial.

$\mathrm{Na}$ verdade, em um primeiro momento, tudo isto foi fator de união e os laços do Brasil com Portugal foram bastante fortalecidos pela vinda da Corte para cá. Esse episódio marcou definitivamente o destino do Brasil independente, que perma- 
neceria ainda muito ligado ao de Portugal, tanto por laços políticos, em virtude de d. Pedro I ser também herdeiro do trono português, quanto por laços simbólicos, pelo fato de continuarmos a viver sob a mesma dinastia que reinava lá.

Isabel Lustosa é pesquisadora da Casa de Rui Barbosa. Principais publicações: D. Pedro I - Um herói sem nenhum caráter (Companhia das Letras, 2006); As trapaças da sorte: ensaios de história e política cultural (EDUfMG, 2004); O nascimento da imprensa no Brasil (Jorge Zahar Editor, 2003); Insultos impressos - A guerra dos jornalistas na Independência (1821-1823) (Companhia das Letras, 200o); coeditora, ao lado de Alberto Dines, da edição fac-similar do Correio Brasiliense (1802-1822), de Hipólito da Costa (Imprensa Oficial do Estado de São Paulo, 2002-2003). 